\title{
Erratum to "Geochemical Characteristics of Released Organic Matters by Acid Decomposition of Hydrocarbon Source Rocks from Different Sedimentary Basins"
}

\author{
Peng Liu $\mathbb{D}^{1},{ }^{1}$ Xiaofeng Wang $\mathbb{D}^{1},{ }^{1}$ Xiaofu $\mathrm{Li}^{2}$ Ting Zhang, ${ }^{3}$ and Wenhui Liu ${ }^{1}$ \\ ${ }^{1}$ State Key Laboratory of Continental Dynamics, Department of Geology, Northwest University, Xi'an 710069, China \\ ${ }^{2}$ Sichuan Key Laboratory of Shale Gas Evaluation and Exploration, Sichuan Coal Field Geology Bureau, Chengdu 610073, China \\ ${ }^{3}$ Key Laboratory of Petroleum Resources Research, Gansu Province, Northwest Institute of Eco-Environment and Resources, \\ Chinese Academy of Sciences, Lanzhou 730000, China
}

Correspondence should be addressed to Xiaofeng Wang; wangxf@nwu.edu.cn

Received 22 July 2020; Accepted 22 July 2020; Published 28 August 2020

Copyright $\odot 2020$ Peng Liu et al. This is an open access article distributed under the Creative Commons Attribution License, which permits unrestricted use, distribution, and reproduction in any medium, provided the original work is properly cited.

In the article titled "Geochemical Characteristics of Released Organic Matters by Acid Decomposition of Hydrocarbon Source Rocks from Different Sedimentary Basins" [1], there was an error in the chemical reaction (2). The error was introduced during the production process of the article, and Hindawi apologises for causing this error. The corrected chemical reaction is shown below,

$$
\mathrm{R}-\mathrm{CO}-\mathrm{O}-\mathrm{R}^{\prime}+\mathrm{H}_{2} \mathrm{O} \rightleftharpoons \mathrm{R}-\mathrm{COOH}+\mathrm{R}^{\prime}-\mathrm{OH}
$$

\section{References}

[1] P. Liu, X. Wang, X. Li, T. Zhang, and W. Liu, "Geochemical characteristics of released organic matters by acid decomposition of hydrocarbon source rocks from different sedimentary basins," Geofluids, vol. 2019, Article ID 4816218, 12 pages, 2019. 